\title{
BLOCK-WISE DISPARITIES IN SOCIO-ECONOMIC CONDITION OF KOCH BIHAR DISTRICT, WEST BENGAL
}

\author{
Sangita Karmakar', Bhupen Barman ${ }^{2}$ and Ranjan Roy ${ }^{3}$ \\ ${ }^{1}$ Research Scholar \& ${ }^{3}$ Professor, \\ Department of Geography \& Applied Geography, North Bengal University, Siliguri, (WB), India \\ Email: sang.tfg@gmail.com, royranjangeo@gmail.com \\ ${ }^{2}$ Assistant Professor, Dept. of Geography, Tufanganj Mahavidyalaya, Cooch Behar, (WB), India \\ Email: bhugeo18@nbu.ac.in
}

\begin{abstract}
The present study attempts to the socio-economic condition and also to assess the pattern of disparities in socio-economic condition at the block level in Koch Bihar district of West Bengal. Out of the total population the rural population is approximately 89.70 percent in the district (Census of India, 2011). The present study focuses on the block level social and economic condition in Koch Bihar district applying the composite score method based on 21 selected demographic, infrastructural and economic development indicators. The level of development assessed separately for, demographic, infrastructural and economic sectors. The blocks are classified into three development categories according to the value of the constructed composite score. An attempt has been made to compare the levels of socio economic development among different blocks of district through thematic maps. The study reveals that the wide disparities in the level of socio economic condition exist among different blocks. The study suggests that low developed blocks require improvement in most of the indicators for enhancing their level of overall socio economic development. It is necessary for the government to move in the direction and rhythm with the society because their sustainability is dependent on the long term benefits derived from the economic and social issues connected to rural basics.
\end{abstract}

Key words: Disparities, Composite Score, Correlation, Socio-Economic Condition

\section{Introduction}

For the betterment of large human groups both economic and social development is very much important. Development means improving the wellbeing of the human being. Development must be evaluated in terms of progressive reduction and elimination of malnutrition, disease, illiteracy, unemployment and inequalities (Thakur, 2008). In the words of Dudly (1972), "If poverty, unemployment and inequality have declined from the high levels than beyond doubt this has been a period of development for the country concerned". Regional disparity means the spatial differences in socio economic development of certain region which reveals the condition of such area as well as the reason behind these differences Economic development is one of the major key components for bringing changes in the overall socio economic development of the people and it also promotes the better standard of living in long term. Regional imbalances in a country may be natural due to unequal distribution of natural and man-made in the sense of neglect or preference of region for investment and infrastructural facilities. In India, still there exist imbalances in every region in respect of socio economic development. The study will help to identify the blocks in Koch Bihar district suffering from backwardness and will be helpful for the policy maker for taking decisions regarding the problem of backwardness.

\section{Objectives}

The presents study aims to investigate the following objectives.

1. To assess the socio economic condition of the blocks and to identify the backward blocks of the district.

2. To study the overall factors responsible for spatial disparities in the socio-economic condition. 


\section{Literature Review}

Pal (1965) made a more systematic attempt in the construction of a composite index of selected variables which permit several stages of analysis in relation to the group of variables to analyse overall development, with a study of all India Level, it may be regarded essentially as a contribution to methodology in areal differentiation by factor analysis. To be of use, in policy decision, these studies need to incorporate some of the important factors like per capita income and production which are directly related to the levels of development. Banerjee (1984) in his article "changing cultural scenario and economic development of India" mainly emphasizes the efforts to achieve economic development. India is facing the problems of massive population growth, rapid depletion of resources, growing disparities between the urban and rural areas as well as regional and social disparities within the country. Dimensions of these problems and their impact on the cultural scenario are important. Banerjee (1992) 49 in his article "Disparities in Development of Socio-economic Infrastructure in rural areas of selected district of Uttar Pradesh", says that diversity in the Sectoral development of different blocks is the main factor responsible for the disparity in the overall development in rural areas. In the project Report sponsored by Planning Commission, Govt. of India, New Delhi, V.K .Bhatia and S.C. Rai (2003-04) discussed that the overall socio-economic development is positively associated with the agricultural development, infrastructural facilities and literacy rate. Infrastructural facilities are found to enhance the level of literacy in the block areas. Socioeconomic development is closely associated with the literacy rate. In order to reduce the disparities in development among different blocks, model blocks have been identified and potential targets of developmental indicators have been estimated for low developed blocks. Low developed blocks require improvements of various dimensions in different indicators for enhancing the level of development. The location specific technology of agricultural development should be adopted and proper utilization of infrastructural facilities and resources should be made.

\section{Data and Methodology}

The study is based on secondary data from various sources particularly from District census Hand book (2011). The composite score method has been used to analyse the spatial variation in socio-economic condition of the district. Keeping in view the existing socio economic condition of the district 21 indicators have been selected and grouped into three categories i.e. demographic, infrastructural and economic.

\section{Demographic indicator}

a. Population density (X1),

b. Sex ratio (X2)

c. Child Sex Ratio (X3)

d. Percentage of SC population (X4)

e. $\quad$ Percentage of ST population (X5)

f. Total literacy rate $(\mathrm{X} 6)$

g. Percentage of male literacy $(X 7)$

h. Percentage of female literacy (X8)

2. Infrastructural indicator

Gender gap in literacy (X9)

a. Percentage of educational institution (X10)

b. Power supply (X11)

c. Doctor population ratio (X12)

d. No. of medical institution per 100000 persons(X13)

e. $\quad$ No. of bed per 1000 persons.(X14)

f. Length of roads in $\mathrm{km}$ (X15)

\section{Economic indicators}

a. Total worker (X16)

b. Percentage of female worker (X17)

c. Percentage of agriculture worker (X18)

d. Bank facilities (X19)

e. Total irrigated land (X20)

f. Percentage of cultivable area to total area.(X21) 


\section{Composite Score Method}

By using these data and indicators an attempt has been made to examine the existing condition of different blocks of Koch Bihar district. $Z$ score has been used to analyse the spatial variation of socio- economic condition.

$$
z_{i}=\frac{x_{i}-\bar{x}}{s}
$$

Where, $Z_{i}$ is the computed $Z$-score $\bar{x}$ is the mean and $S$ is the standard deviation (SD). For categorising the blocks mean and SD value has been calculated. Then SD is divided by 2 and Half of SD is added with mean value to form 'high' category and half of SD is subtracted from mean to form 'low' category and rest values lying between high and low category comes under 'medium' category. Finally, correlation matrix has been shown to show the relationship between demographic, infrastructural and economic with each other and with overall development. The composite score of demographic, infrastructural and economic indicators present overall scenario of Koch Bihar district. The blocks have been classified into three groups based on these computed values.

\section{Study Area}

Koch Bihar is a district of West Bengal in the foothills of Himalaya. Koch Bihar lies in the North Eastern part of West Bengal, bounded by the district of Alipurduar in the North, Jalpaiguri in the North- West, State of Assam in the East and International border in the form of IndoBangladesh boundary in the South-West, South and South-East. It lies between $25^{\circ} 57^{\prime} 47^{\prime \prime} \mathrm{N}$ and $26^{\circ} 36^{\prime} 20^{\prime \prime} \mathrm{N}$ and $88^{\circ} 47^{\prime} 44^{\prime \prime} \mathrm{E}$ to $89^{\circ} 54^{\prime} 35^{\prime \prime} \mathrm{E}$ with the total area of 3387 square kilometres having population of 2819086 with the density of 832 persons per square kilometres as per 2011 census. The district comprises 12 blocks namely Haldibari, Mekhligang, Mathabhanga I, Mathabhanga II, Koch Bihar I, KochBihar II, Tufanganj I, Tufanganj II, Dinhata I, Dinhata II, Sitai and Sitalkuchi. The areas mainly based on agricultural activities.

\section{ANALYSIS AND DISCUSSION Level Of Demographic Condition}

Table 01: Z Score Values of Demographic Indicators

\begin{tabular}{|l|l|l|l|l|l|l|l|l|l|l|l|}
\hline $\begin{array}{l}\text { Name of the } \\
\text { Blocks }\end{array}$ & $\mathbf{X 1}$ & $\mathbf{X 2}$ & $\mathbf{X 3}$ & $\mathbf{X} \mathbf{1}$ & $\mathbf{X 5}$ & $\mathbf{X 6}$ & $\mathbf{X 7}$ & $\mathbf{X 8}$ & $\mathbf{X 9}$ & $\begin{array}{l}\text { Composite } \\
\text { score }\end{array}$ & Levels \\
\hline Haldibari & -0.53 & 1.37 & 0.85 & 0.51 & -0.57 & -0.68 & -0.71 & -0.63 & 0.04 & -0.039 & Moderate \\
\hline Mekhliganj & -1.82 & -0.29 & -1.54 & 1.59 & 0.89 & -0.73 & -0.49 & -0.96 & 1.87 & -0.164 & Low \\
\hline Mathabhanga I & -0.53 & -0.20 & -0.31 & 1.21 & -0.94 & -0.15 & 0.07 & -0.37 & 1.55 & 0.039 & Moderate \\
\hline Mathabhanga II & -0.17 & -0.06 & -0.85 & 0.86 & 0.98 & 0.12 & 0.22 & 0.03 & 0.58 & 0.189 & High \\
\hline KochBihar I & 0.59 & -0.29 & -0.62 & -1.23 & -0.43 & 0.76 & 0.71 & 0.81 & -0.68 & -0.043 & Moderate \\
\hline KochBihar II & 0.22 & -1.98 & 1.23 & -0.69 & 0.67 & 1.93 & 1.82 & 1.97 & -1.34 & 0.426 & High \\
\hline Tufanganj I & 0.12 & -0.42 & -0.77 & -0.90 & -0.80 & 0.34 & 0.30 & 0.37 & -0.37 & -0.236 & Low \\
\hline Tufanganj II & -0.52 & -0.18 & 0.77 & -0.08 & 2.31 & 0.79 & 0.86 & 0.71 & 0.12 & 0.531 & High \\
\hline Dinhata I & 1.83 & -0.19 & -0.08 & -1.05 & -0.40 & 0.20 & 0.02 & 0.37 & -1.23 & -0.058 & Moderate \\
\hline Dinhata II & 1.65 & -0.91 & -1.08 & -1.09 & -0.25 & 0.04 & -0.11 & 0.15 & -0.85 & -0.272 & Low \\
\hline Sitai & -0.51 & 1.51 & 1.31 & 0.96 & -0.74 & -2.17 & -2.33 & -2.00 & -0.11 & -0.453 & Low \\
\hline Sitalkuchi & -0.36 & 1.30 & 1.08 & -0.10 & -0.81 & -0.42 & -0.37 & -0.44 & 0.40 & 0.029 & Moderate \\
\hline
\end{tabular}

Source: Compiled by author

The demographic composition of any region has a close bearing to the level of development. Population density, sax ratio, child sex ratio, total literacy, male literacy, female literacy, percentage share of SC and ST population, Gender gap in literacy those 9 (X1 to X9) are considered as demographic indicators and computed by composite score. The pattern of spatial distribution shows the inter block disparities in terms of demographic characteristic (figure 1).

Less Developed Region: This region consists of 4 blocks namely Tufanganj I, Dinhata II and Sitai, Mekhliganj having least composite score $(<-0.145)$ in terms of demographic indicators .These blocks are suffering from backwardness and having a unfavourable condition of density, sex ratio, literacy rate etc. 
Moderate Developed Region: The blocks having the composite value between -0.145 to 0.137 are considered as moderate developed regions consisting 5 blocks namely Haldibari, Mathabhanga I, KochBihar I, Dinhata I and Sitalkuchi.

High Developed Region: The high developed region consists of 3 blocks namely Mathabhanga II, Koch Bihar II, and Tufanganj II. These are due to reason of that Koch Bihar II is the head quarter of the district. These three blocks are having favourable male female ratio, population density and SC \& ST population literacy rate etc.

Level of Infrastructural Condition: Infrastructural disparities (figure 2) have many causes ranging from historical to present status in health, education and other such amenities (Ram, 1995). Based on the composite score of 6 indicators the blocks are grouped into three categories in order to explain the present inter block level disparities.

Table 02: Z Score Values for Infrastructural Indicators

\begin{tabular}{|l|l|l|l|l|l|c|c|c|}
\hline $\begin{array}{l}\text { Name of the } \\
\text { Blocks }\end{array}$ & $(\mathrm{X} 10)$ & $(\mathrm{X} 11)$ & $(\mathrm{X} 12)$ & $(\mathrm{X} 13)$ & $(\mathrm{X} 14)$ & $(\mathrm{X15})$ & $\begin{array}{l}\text { Composite } \\
\text { Score }\end{array}$ & Levels \\
\hline Haldibari & -1.39 & -1.16 & -0.70 & 2.14 & 0.06 & -1.32 & -0.40 & Low \\
\hline Mekhliganj & -0.58 & 0.90 & -0.84 & -0.07 & 0.43 & -0.53 & -0.11 & Moderate \\
\hline Mathabhanga I & -0.23 & -0.27 & -0.87 & -1.47 & 0.22 & -0.62 & -0.54 & Low \\
\hline Mathabhanga II & 0.47 & 0.45 & 0.54 & -1.34 & -0.80 & -0.12 & -0.13 & Moderate \\
\hline KochBihar I & 1.69 & 2.11 & -1.10 & 0.17 & 2.70 & 2.08 & 1.27 & High \\
\hline KochBihar II & 1.24 & -0.06 & 0.08 & -0.07 & -0.12 & 0.91 & 0.33 & High \\
\hline Tufanganj I & 0.06 & -0.64 & -0.83 & 1.11 & 0.14 & -0.03 & -0.03 & Moderate \\
\hline Tufanganj II & -0.21 & -0.88 & 1.12 & 0.43 & -0.84 & 1.32 & 0.16 & Moderate \\
\hline Dinhata I & 0.79 & 1.19 & -0.84 & 0.27 & 0.53 & -0.42 & 0.25 & Moderate \\
\hline Dinhata II & 0.48 & 0.02 & 1.86 & -0.94 & -0.79 & 0.09 & 0.12 & Moderate \\
\hline Sitai & -1.64 & -1.10 & 0.48 & 0.00 & -0.69 & -1.21 & -0.69 & Low \\
\hline Sitalkuchi & -0.68 & -0.57 & 1.10 & -0.23 & -0.83 & -0.15 & -0.23 & moderate \\
\hline
\end{tabular}

Source: Compiled by author

Less Developed Region: Haldibari, Sitai and Mthabhanga I fall under this group having the least value i.e. $<-0.255$. These blocks are less developed due to less number of educational institutions, power supply, having unfavourable doctor population ratio, number of medical institution etc.

Moderate Developed Region: The category having range score of $-0.254-0.254$ which includes 7 blocks namely Mekhliganj, Sitalkuchi, Mathabhanga II, Dinhata I, Dinhata II, Tufanganj I, Tufanganj II, Koch Bihar II. The blocks have moderate number of amenities which resulted in order moderate state of development.

High Developed Region: only Koch Bihar I and Koch Bihar II blocks come under this category due to it is the district head quarter having adequate number of schools, health centres, power supply etc.

\section{Level of Economic Condition:}

The blocks are also divided into less economic development based on the computed score considering such indicators (figure 3 ).

Table 03: Z-Score Values for Economic Indicators

\begin{tabular}{|l|c|c|c|c|c|c|c|c|}
\hline $\begin{array}{l}\text { Name of the } \\
\text { blocks }\end{array}$ & $\mathrm{X} 16$ & $\mathrm{X} 17$ & $\mathrm{X} 18$ & $\mathrm{X} 19$ & $\mathrm{X} 20$ & $\mathrm{X} 21$ & $\begin{array}{l}\text { composite } \\
\text { score }\end{array}$ & Levels \\
\hline Haldibari & -1.135 & -0.807 & -1.087 & 1.859 & 0.760 & 2.295 & 0.314 & High \\
\hline Mekhliganj & 0.270 & 0.459 & 2.641 & -0.824 & -0.372 & -0.587 & 0.265 & High \\
\hline Mathabhanga I & 1.746 & 1.628 & 0.311 & 0.904 & -0.555 & 1.258 & 0.882 & High \\
\hline Mathabhanga II & -0.377 & -0.338 & -1.087 & -0.355 & -2.582 & -1.462 & -1.034 & Low \\
\hline Koch Bihar I & 0.336 & 0.288 & -0.155 & -1.059 & 0.591 & 0.349 & 0.058 & Moderate \\
\hline Koch Bihar II & -1.217 & -1.388 & 0.311 & -1.259 & 0.377 & 0.078 & -0.516 & Low \\
\hline Tufanganj I & -0.082 & -0.367 & -0.621 & 1.579 & 0.341 & 0.594 & 0.241 & Moderate \\
\hline Tufanganj II & -0.316 & -0.363 & 0.311 & 0.140 & -0.980 & -0.392 & -0.267 & Low \\
\hline Dinhata I & -0.373 & -0.474 & 0.311 & -0.380 & 0.883 & -0.185 & -0.036 & Moderate \\
\hline Dinhata II & -0.406 & -0.857 & -0.621 & 0.306 & 0.239 & -1.225 & -0.427 & Low \\
\hline Sitai & 2.045 & 2.025 & -0.621 & -0.296 & 0.828 & -0.017 & 0.661 & High \\
\hline Sitalkuchi & -0.471 & 0.193 & 0.311 & -0.613 & 0.469 & -0.706 & -0.136 & Moderate \\
\hline
\end{tabular}

Source: Compiled by author 
Less Developed Region: Blocks namely Mathabhanga II, Koch Bihar II, Dinhata II, Tufanganj II are less developed having the least score <-0.264. The low development is due to low percentage of net shown area, lack of irrigation, in adequacy of worker, having no bank facilities etc.

Moderate Developed Region: The zone comprises 4 blocks namely Sitalkuchi, Koch Bihar I, Dinhata I, Tufanganj I. These blocks have moderate level in terms of net shown area, total irrigated land, adequate worker. All these indicators helped these blocks to figure in moderate developed region in terms of economy.

High Developed Region: Haldibari, Mekhliganj, Mathabhangal, Sitai These blocks are having adequate level of net shown area, irritated land worker and all these have placed the blocks in highly developed region. (>0.264).

Figure-1

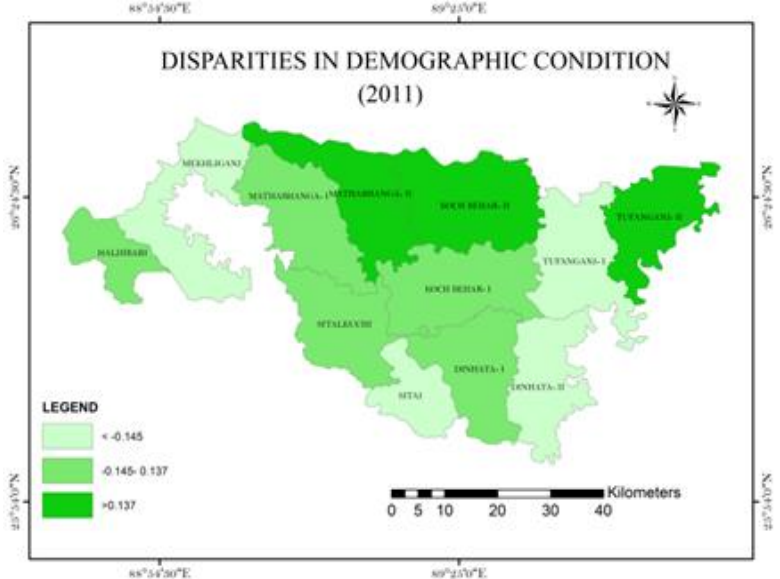

Figure-3

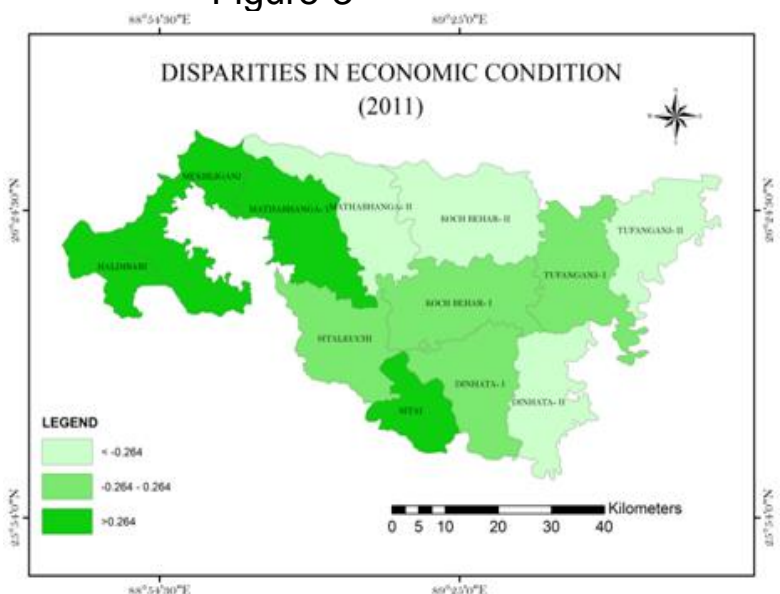

Figure-2

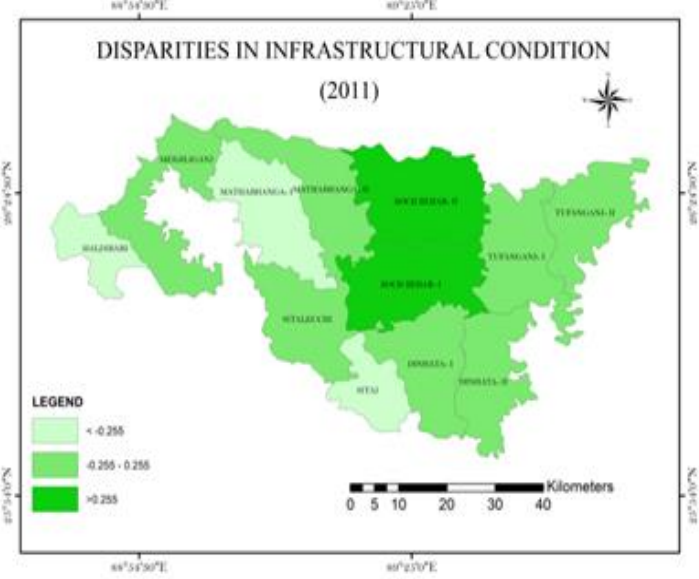

Figure-4

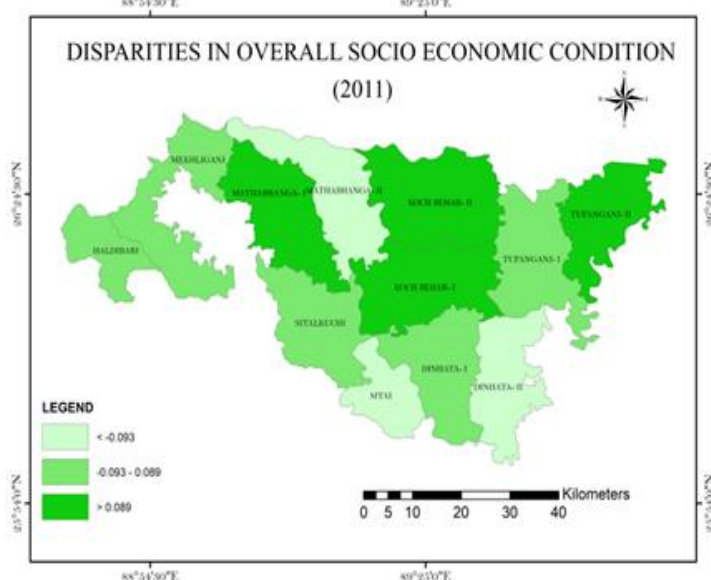

\section{Overall Socio-Economic Condition}

The analysis of sectoral development brought out the fact that by itself each block does not have the same level of infrastructural, economic and demographic condition. Some blocks may have high level of infrastructural development whereas the other have well places in demographic or economic terms, while overall socio economic condition may show different result. These indicators have to be further analysed whether there are any connection among them and resulting a different pattern of overall socio economic condition (figure 4).

Less Developed Region: The blocks having the value of $<-0.093$ are considered as less developed regions, There are 3 blocks namely Mathabhanga II, Dinhata II, Sitai. These 3 blocks are most backward blocks due to low development categories mainly due to lack of irrigation, lack of net shown area, unfavourable sex ration, population density, low level of literacy, educational institution etc. These are the least developed blocks of districts in terms of overall socio economic development.

Moderate Developed Region: 5 blocks fall under this group ranging the score $-0.092-0.088$ blocks are mainly Haldibari, Mekhliganj, Dinhata I, Tufanganj II, and Sitalkuchi. The moderate 
presence of all infrastructural, economic and demographic indicators has placed these blocks in moderate developed region.

High Developed Region: On the basis of aggregate score, the highly developed region consists of 3 blocks namely Mathabhanga I, Koch Bihar I, Koch Bihar II, and Tufanganj II. These blocks are having prominent sex-ratio, population density, literacy rate, good number of educational intuition, health centres, net shown area, irrigation, power supply etc. All these have made the blocks highly developed region in terms of overall socio economic development. The blocks that are highly developed in terms of economic and demographic factors also show significant growth and development in terms of land use and agricultural efficiency.

Table 04: Composite Score for Various Sectors
\begin{tabular}{|l|c|c|c|c|}
\hline Name of the Blocks & $\begin{array}{l}\text { Demographic } \\
\text { Sector }\end{array}$ & $\begin{array}{l}\text { Infrastructural } \\
\text { Sector }\end{array}$ & $\begin{array}{l}\text { Economic } \\
\text { Sector }\end{array}$ & $\begin{array}{l}\text { Overall Socio-Economic } \\
\text { Development }\end{array}$ \\
\hline Haldibari & -0.039 & -0.397 & 0.314 & -0.040 \\
\hline Mekhliganj & -0.164 & -0.113 & 0.265 & -0.027 \\
\hline Mathabhanga I & 0.039 & -0.542 & 0.882 & 0.114 \\
\hline Mathabhanga II & 0.189 & -0.134 & -1.034 & -0.253 \\
\hline Koch Bihar I & -0.043 & 1.274 & 0.058 & 0.362 \\
\hline Koch Bihar II & 0.426 & 0.332 & -0.516 & 0.130 \\
\hline Tufanganj I & -0.236 & -0.030 & 0.241 & -0.041 \\
\hline Tufanganj II & 0.531 & 0.157 & -0.267 & 0.196 \\
\hline Dinhata I & -0.058 & 0.253 & -0.036 & 0.037 \\
\hline Dinhata II & -0.272 & 0.121 & -0.427 & -0.204 \\
\hline Sitai & -0.453 & -0.695 & 0.661 & -0.204 \\
\hline Sitalkuchi & 0.029 & -0.227 & -0.136 & -0.091 \\
\hline
\end{tabular}

Source: Compiled by author

Table 05: Level of Overall Socio-Economic Condition

\begin{tabular}{|l|l|}
\hline \multicolumn{1}{|c|}{ Level of development } & \multicolumn{1}{c|}{ Name of the blocks } \\
\hline High $(>0.089)$ & Mathabhanga I, KochBihar I, KochBihar II, Tufanganj II \\
\hline Moderate $(-0.093-0.089)$ & Haldibari, Mekhliganj, Dinhata I, Tufanganj II, Sitalkuchi \\
\hline Low $(<-0.093)$ & Mathabhanga II, Dinhata II, Sitai \\
\hline
\end{tabular}

\section{Correlation among Major Developmental Variables}

Correlation matrix indicates that demographic, infrastructural, economic and overall socioeconomic developments are positively and significantly correlated with each other.

Table 06: Correlation Matrix

\begin{tabular}{|l|c|c|c|c|}
\hline Category & Demographic & Infrastructural & Economic & Overall development \\
\hline Demographic & 1 & & & - \\
\hline Infrastructural & 0.270 & 1.000 & & - \\
\hline Economic & $-0.505^{\star}$ & -0.383 & 1.000 & - \\
\hline Overall development & 0.463 & $0.665^{\star *}$ & 0.188 & 1 \\
\hline
\end{tabular}

Source: Compiled by author

${ }^{*}$ Correlation is significant at the 0.05 level.

** Correlation is significant at the 0.01 level.

Demographic and economic condition is positively associated with over all development $(0.463)$ and $(0.118)$. But economic condition is negatively correlated with both demographic and infrastructural development. This is mainly due to the infrastructural facilities are concentrated in certain areas where net shown area, cultivable land, working population sex ratio, literacy rate etc. are not equally concentrated. Infrastructural condition is also positively associated with over all development (0.665) at 0.01 significant levels.

\section{Conclusion}

The analysis reveals that there exist wide regional disparities in sectoral and spatial development in the district. Diversity in the Sectoral development of different blocks is the main factor responsible for the disparity in the overall development in the district. It also reveals that Mathabhanga II, Dinhata II, and Sitai these 3 blocks are most backward blocks of the district where as Mathabhanga I, KochBihar I, Koch Bihar II, and Tufanganj II are high developed regions in terms of overall socio economic condition. Therefore, it is important to say that 
Government should look into the faster and proper development of each sector at grass root level for the moderate and low developed blocks.

\section{References}

1. Angadi, D.P. (2012) Regional Disparities in Agriculture Development, A case study of Bengaum District in Karnataka state, India, Regional Symbiosis Vol.20, pp. 68-86.

2. Banarjee, B. (1984) Changing Cultural Scenario and economic development of India, Geographical Review of India, Vol. 46, Number 2, June 1984, pp. 516.

3. Banerjee, Smith (1992) Disparities in development of socio-economic infrastructure in rural areas of selected districts of Uttar Pradesh. Geographical review of India .Vol. 54. March 1992, No. I, pp. 31, Calcutta

4. Bhatia, V. K. and Rai, S.C (2003-04). Indian Society of Agricultural Statistics IASRI Campus, Library Avenue, Pusa New Delhi - 110012 (2003 - 2004)

5. Chandna, R. C. and Sidhu M.S. (1980) Introduction to Population Geography, New Delhi.

6. District Census Handbook, Koch Bihar, 2001 \& 2011

7. Dudly, Seers (1972) The Meaning of Development in Norman. T. Uphoff and Warren F .I. Ichman ed., The political Economy of Development, Barkley University of California Press.

8. Krishna, G and N. Singh (1998) Regional and intra-Regional disparities in India." Geography Vol. 20, No. 1 \& 2, June- Dec, pp .111-121.

9. Pal, M.N (1975). Regional disparities in the Level of development of India ", Indian Journal of Regional Science, Vol. VIII. No.1

10. Pal, M.N. (1965) Regional Disparities of India, Resource development in India, Fifth Econometric Conference, New Delhi, 1965.

11. Ram, Paras (1995) Inter -district Disparities in the level of Socio- Economic development in Himachal Pradesh, A Ph.D. Dissertation submitted to Department of Economics H.P University, Shimla .

12. Saur, D. (1984) Development Indicators and Regional Disparity in Orissa: A Factor Analytic Study, Indian Journal of Regional Science, Vol. 16, No. 2, pp. 108-20

13. Thakur, Shilpa (2008) Socio- Economic Development of Mandi District, M.Phil. Dissertation submitted to Department of Geography H.P .University Shimla. 